\title{
Correction to: Cancer risk from chronic exposures to chemicals and radiation: a comparison of the toxicological reference value with the radiation detriment
}

\author{
Enora Cléro $^{1}$ Michèle Bisson ${ }^{2} \cdot$ Velly Nathalie $^{2} \cdot$ Eric Blanchardon $^{1} \cdot$ Eric Thybaud $^{2} \cdot$ Yann Billarand $^{1} \mathbb{D}$
}

Published online: 28 September 2021

๑) Springer-Verlag GmbH Germany, part of Springer Nature 2021

\section{Correction to: Radiation and Environmental Biophysics https://doi.org/10.1007/s00411-021-00938-2}

Authors would like to correct the error in their publication.

Footnote of table 2 updated as below.

*For the general population, age $0-89$ years at exposure updated from ICRP 2007.

The original article has been corrected.

Publisher's Note Springer Nature remains neutral with regard to jurisdictional claims in published maps and institutional affiliations.

The original article can be found online at https://doi.org/10.1007/ s00411-021-00938-2.

Yann Billarand

yann.billarand@irsn.fr

1 Health and Environment Division, Institute for Radiological Protection and Nuclear Safety (IRSN), BP 17,

92262 Fontenay-aux-Roses Cedex, France

2 Chronic Risks Division, French National Institute for Industrial Environment and Risks (INERIS), Parc technologique Alata - BP 2, 60550 Verneuil-en-Halatte, France 